\title{
EL PROFUNDO ESPEJO DEL DESEO. NUEVAS PERSPECTIVAS CRÍTICAS EN TORNO A LA POÉTICA DE DELMIRA AGUSTINI. I PREMIO DE INVESTIGACIÓN FILOLÓGICA "PROFESOR JOSÉ ROMERA CASTILLO"
}

\author{
Mirta FERNÁNDEZ DOS SANTOS
}

Madrid: Editorial Verbum, 2020, 353 pp.

ISBN: 9788413373751

El libro de Mirta Fernández Dos Santos revela un conocimiento exhaustivo de la vida, obra y recepción crítica de la poeta uruguaya Delmira Agustini. El extraordinario y sistemático esfuerzo de documentación, lectura de fuentes, examen del epistolario, revisión de cuadernos manuscritos — con esmerada descripción incluso gráfica y física de los mismos_-, fotografías, artículos periodísticos, pinturas, piezas de teatro y demás material complementario y paratextual queda manifiesto en este ensayo abarcador que aborda múltiples aspectos de su figura y producción y que es fruto de una tesis doctoral elaborada a lo largo de varios años bajo la dirección de Ángeles Estévez en la UNED. El estudio de las variantes de sus poemas, por otra parte, me parece muy original y uno de los hallazgos más relevantes y reveladores del libro, así como el trabajo minucioso con el léxico y aspectos morfológicos adyacentes de su poesía, cuya lectura e interpretación personal es realmente apasionante y deja ganas de mayor continuidad en tan desafiante tarea. Los criterios ortotipográficos -importantes en una obra con tantas variantes y editada con tan poco cuidado a lo largo de las décadas como la de Agustini- están bien argumentados y, aunque siempre cuestionables, revelan libertad, ejercicio detenido de reflexión y firmeza filológica. Confío en que esta sea, de hecho, una de las líneas que la profesora Dos Santos explore próximamente porque no hay duda de que el estudio de las concordancias y el vocabulario de Los cálices vacíos arroja aquí luz inédita sobre la obra de la creadora, sus motivaciones, inseguridades, derivas y proyecciones. Esto, junto a los tanteos, dudas, correcciones y exclusión consciente de algunos inéditos por parte de la propia autora, es uno de los aspectos más interesantes en la indagación y reconstrucción de su ejercicio como escritora con voluntad y dominio pleno de su tarea y oficio y mostraría los entresijos del laboratorio de escritura - recomiendo completar la visión, por cierto, con el número de la uruguaya revista SIC que está dedicado de manera 
monográfica a Literatura de mujeres y género $(8$, abril 2014) y, en concreto, remito al formidable trabajo de interpretación de sus semblanzas femeninas en La Alborada por parte del crítico Néstor Sanguinetti-.

Todo este ingente trabajo que acabo de referir ha hecho posible que Fernández Dos Santos no solo haya publicado este ensayo que ha obtenido el I Premio de Investigación Filológica "Profesor José Romera Castillo" y que ha procedido a editar Verbum, sino que haya acometido la delicada y riesgosa tarea de editar la poesía de Delmira Agustini para Visor, editorial con amplísima difusión y recepción en todos los países de América Latina con la responsabilidad filológica y crítica que esto implica, así como otro ensayo crítico que vió la luz en 2019 en la prestigiosa editorial Iberoamericana-Vervuert (La recepción crítica de la obra de Delmira Agustini por sus contemporáneos (a través de su correspondencia inédita y poco difundida)). Todo ello muestra que los resultados de la investigación están encontrando, pues, espacio y exquisito acomodo.

Me interesa mucho la doble mirada de la Doctora Dos Santos hacia la alta cultura y la cultura popular y sus intersecciones y paradojas, lo que se muestra en la huella que la poeta uruguaya dejó impresa en las manifestaciones artísticas y disciplinas más diversas y heterogéneas. Sin embargo, discrepo ligeramente en cierta idealización de la artista - en la que es lícito caer por il fascino del inapresable y poliédrico objeto de estudiosin reparar en la calidad estética no siempre incuestionable de su creación - lo que atañe, a mi entender, especialmente a sus escasas dotes pictóricas por lo que dudo que esta sea, como afirmara Romiti y afirma Dos Santos, una vertiente valiosa por trabajar- En este sentido iría también mi principal objeción a la reflexión teórico-crítica, en general sesuda, bien pergeñada, lúcida e inteligente de la autora: y es la que tiene que ver con no discriminar entre aproximaciones críticas autorizadas, documentadas, bien elaboradas, sólidas como las de Eleonora Crócquer, Carina Blixen, Magdalena García Pinto, Rosa García Gutiérrez, Ana Inés Larre Borges o Jacqueline Girón Alvarado y otras perspectivas, en mi opinión bastante caducas desde una mirada crítica actual, como las de Manuel Alvar, Arturo Sergio Visca, Zum Felde, Ofelia Machado de Benvenuto, Uruguay Cortazzo o Alejandro Cáceres. Una cosa es conocer en detalle, con rigor todas las fuentes y estudios críticos y otra no marcar la distinción —en investigación hay que arriesgarentre la calidad y proyección de dichos estudios — la edición de la poesía de Agustini llevada a cabo por Cáceres es unánimemente considerada en términos académicos y críticos incompleta, con algunos errores y notables carencias o simplificaciones-. A este respecto, considero que se debería tener enorme cautela y tratar de no colocar al mismo nivel crítico ensayos y estudios que tienen entre sí una distancia temporal de 50 o 60 años, pero también una distancia abismal en profundidad, precisión y rigor. ¿Por qué citar a Martínez Moreno y no a Hervé Le Corre, por ejemplo, cuando se habla de posmodernismo como corriente epigonal del modernismo?

Me ofrece, por otra parte, algunas dudas la ubicación de la escritura de Delmira Agustini en una fase de experimentación vanguardista o posmodernista. Es su imaginario, lenguaje y conciencia radicalmente modernista en mi opinión. No busca más allá. 
Tampoco es necesario porque lo que Agustini decide hacer es dar ese giro al esteticismo modernista en el lugar de enunciación y eso lo hace muy bien, por lo que se sitúa justamente en el centro neurálgico de la estética que hizo del simbolismo una forma hispánica con ritmo y verbo propios, modulándolo desde una perspectiva de género. Disiento en la idea de que decadentismo y dandismo sean "dos formas de cristalización del exceso finisecular" por la disparidad de las propuestas, estética una, vital y sociocultural la otra. En cualquier caso, sería pertinente ampliar la mirada a la excentricidad de raíz oriental con una referencia crítica al monográfico Raros uruguayos que editaron Javier Uriarte y Valentina Litvan en 2011 en Cuadernos LI.RI.CO. y que se ha convertido en un referente sobre el asunto conceptual de le peculiaridad y la pose en los artistas uruguayos desde Lautréamont o Roberto de las Carreras hasta Delmira Agustini o Marosa di Giorgio.

Por otra parte, es interesante la comparativa con la escritura de otras poetas incontestables del Cono Sur como Mistral, Ibarbourou o Storni — que, además de una conferencia, le dedica algunos poemas - , aunque habría que dejar constancia de que se desea trascender el compartimento estanco de lo femenino como categoría aparte que se ha perpetuado durante tantas décadas y que convendría desterrar de la crítica contemporánea. Hay, en mi opinión, más intertextualidad y una mayor cercanía en la tradición asimilada con la menos conocida María Eugenia Vaz Ferreira — aunque ninguna de las dos fue miembro de facto de la Generación del 900 cuyos espacios y tertulias les eran vedadas a ambas por mujeres salvo en circunstancias excepcionales-, con Albert Samain, Rachilde o Baudelaire que con Gabriela Mistral o Alfonsina Storni. Estaría muy bien completar esta reflexión con una mención al monográfico de la revista Ínsula del año 2014 que, a los cien años de su muerte, incorpora trabajos de Peri Rossi, Aínsa, Blixen, García Gutiérrez y Bruña y que marcó un punto de inflexión en su recepción crítica junto a Lo que los archivos cuentan en Uruguay que se vincula muy estrechamente al proyecto de digitalización del archivo en la Biblioteca Nacional al que la académica se refiere con pertinencia en bastantes ocasiones en su libro.

Este ensayo trasluce mucho trabajo, profesionalidad, dedicación y un dominio absoluto de las fuentes críticas sobre Delmira Agustini. Es esforzado, pormenorizado y ambicioso. Y deja ganas de más, especialmente en lo que concierne a la traducción al portugués ibérico de su poesía - lo que le dará una visibilidad necesaria a su obra en el país vecino- y la ampliación lexicográfica del estudio del vocabulario y las concordancias morfológicas a toda su producción, lo que iluminaría de una forma original y nueva la configuración de una lengua literaria propia en Agustini, de un estilo - hasta ahora comprobado por la Doctora Dos Santos solo en Los cálices vacíos por limitaciones lógicas de espacio y tiempo-. Un estilo que nace del impulso esencial de la poesía que se sitúa, como en Safo antes, como en Cernuda después, entre la realidad y el deseo, entre el placer y el dolor, sin que esto implique inadaptación o tortura sino simple y llanamente sensibilidad, búsqueda de un lenguaje otro, conocimiento, arte. Es una espléndida noticia contar con este libro cabal que abre multitud de cauces y caminos — desde lo genético o 
ecdótico hasta lo lexicográfico, filológico o crítico- . No puedo sino felicitar a su autora y a Verbum por la iniciativa de dar acogida, cuando no sobran espacios de calidad para ello, al I Premio de Investigación Filológica "Profesor José Romera Castillo", creado por la Facultad de Filología de la UNED, en reconocimiento a la labor llevada a cabo por el mencionado profesor.

María José Bruña Bragado

Universidad de Salamanca

This work is licensed under a Creative Commons AttributionNonCommercial-NoDerivatives 4.0 International (CC BY-NC-ND). 